\title{
Addition of nucleoside analogues to peg-IFNa-2a enhances virological response in chronic hepatitis B patients without early response to peg-IFNa-2a: a randomized controlled trial
}

Yan Xu, Xu Wang, Zhenhua Liu, Changyu Zhou, Wenqian Qi, Jian Jiao, Fan Yu, Honghua Guo, Ping Zhao and Jiangbin Wang ${ }^{*}$

\begin{abstract}
Background: Current treatments for chronic hepatitis B (CHB) include pegylated interferon alpha (PEG-IFN-a) which is an immune modulator, and nucleos(t)ide analogs (NAs) which directly inhibit HBV DNA polymerase. With the limited efficacy of PEG-IFN- $a$ and prolonged treatment periods associated with NAs, there is an urgent need for novel therapeutic strategies, especially for patients with a poor early response to anti-viral therapy.

Methods: In this study, 178 patients with chronic hepatitis B $(n=131)$ and compensated $(n=47)$ HBV-induced cirrhosis were enrolled, 120 patients with HBeAg (+). All the patients were treated for 12 weeks with PEG-IFN-a. Among them, a total of 138 patients with a poor virological response after 12 weeks were treated for an additional 48 weeks with Peg-IFNa-2a (control) $(n=43)$, with Peg-IFNa-2a + entecavir (ETV) $(n=49)$, or Peg-IFNa-

$2 a+$ adefovir dipivoxil (ADV) $(n=46)$, and were followed for 48 weeks after therapy. Early virological response was defined as undetectable HBV DNA after anti-viral therapy for 12 weeks. Sustained virological response (SVR) was defined as no change in therapeutic effectiveness after 6 months follow-up, and no recurrence.Therapeutic efficacy was determined by evaluating HBV DNA levels, serum and liver HBsAg levels, liver function tests and liver histology.

Results: Patients in the Peg-IFNa-2a + ETV and Peg-IFNa-2a + ADV groups showed a significantly greater decrease in HBV DNA levels over time, and a significantly higher SVR compared to patients receiving Peg-INFa-2a monotherapy (both $P$ values $<0.05$ ). Although patients receiving combination therapy had a significantly higher change in serum HBsAg levels compared to the monotherapy group, there was no significant difference in liver HBsAg levels between the three treatment groups.
\end{abstract}

Conclusion: This study demonstrated that in patients with a poor virological response after 12 weeks of treatment with Peg-IFNa-2a alone, addition of ADV or ETV significantly reduced HBV DNA levels, serum HBsAg levels, and increased SVR. Individualization of anti-viral therapy would ensure that only patients who do not respond to PegIFNa-2a would receive combination therapy. Our data have important implications for the treatment of CHB patients who fail to show an early response to Peg-IFNa-2a monotherapy.

Trial registration: This trial was retrospectively registered on 2012 May 24 at the China Clinical Trials Registry (ChiCTR-OCC-12002196).

Keywords: Chronic hepatitis B, Interferon, Nucleoside analog, Virological response, Combination therapy

\footnotetext{
* Correspondence: zrlwangjb@medmail.com.cn

Department of Gastroenterology, China-Japan Union Hospital, Jilin

University, Changchun, Jilin Province 130033, China
} 


\section{Background}

It is estimated that approximately 350 million people worldwide are chronically infected with the hepatitis $B$ virus (HBV) [1], and a large percentage of these patients have been shown to be at increased risk of developing liver cirrhosis or hepatocellular carcinoma (HCC) $[2,3]$. The primary therapeutic goals in patients with chronic hepatitis $\mathrm{B}(\mathrm{CHB})$ are clearance of the hepatitis $\mathrm{B}$ surface antigen (HBsAg) from the serum, which is associated with normalization of ALT and histological improvement of inflammation and fibrosis $[4,5]$.

Currently approved treatments for $\mathrm{CHB}$ include two categories of drugs: 1) immune modulators such as PegINF $\alpha-2 \mathrm{a}$, and 2) nucleoside (lamivudine, entecavir and telbivudine) and nucleotide analogs (adefovir dipivoxil and tenofovir disoproxil fumarate), which suppress viral replication by selectively inhibiting the activity of $\mathrm{HBV}$ DNA polymerase. Although nucleos(t)ide analogues (NAs) are cheap and safe, their limited long-term efficacy result in prolonged treatment periods, particularly in patients with $\mathrm{HBeAg-negative} \mathrm{CHB}$. Extended use of NAs has been shown to be associated with the generation of drug-resistant mutations [6]. In contrast, the duration of interferon-based therapy is predetermined and finite. However, only $30 \%$ of $\mathrm{HBeAg}$-negative $\mathrm{CHB}$ patients treated with Peg-INF $\alpha-2 \mathrm{a}$ achieve a sustained virologic response (SVR) off-treatment, and HBsAg seroconversion in seen in 3-4\% of patients after 1 year of treatment [7]. Although it was recently shown that CHB patients treated with PEG-IFN had higher rates of $\mathrm{HBeAg}$ seroconversion and HBsAg seroclearance compared to those treated with entecavir (ETV) [8], interferons have been shown to be effective only in patients with low viral loads, when the ALT levels are $>2-5$ ULN, or in patients infected with $\mathrm{HBV}$ genotype A/B. Additionally, although the rate of HBV DNA loss with interferon-based therapy can range from $14 \%-58.6 \%$, more than $50 \%$ of the patients show low levels of viral replication, especially those with a poor early response to Peg-IFN [9-12]. Other challenges with using interferon-based therapy include the need for parenteral administration, frequent clinical follow-ups and the side-effects.

There has been a recent focus on developing novel therapeutic strategies for patients with a poor response to PegINF- $\alpha-2 \mathrm{a}$. Some studies have combined the immunomodulatory properties of Peg-IFN along with the direct anti-viral activity of NAs in an attempt to improve therapeutic efficacy in $\mathrm{CHB}$ patients. Patients treated with a combination of Peg-INF $\alpha$ and lamivudine (LAM) had a higher ontreatment virological response rate compared to patients treated with LAM monotherapy, but there was no improvement in post-therapy response rates $[9,10]$. Similarly, although $\mathrm{HBeAg}$-negative $\mathrm{CHB}$ patients treated with a combination of Peg-INF- $\alpha-2 \mathrm{a}$ and adefovir dipivoxil (ADV) had a more rapid on-treatment HBV DNA suppression compared to those treated with Peg-INF- $\alpha-2 \mathrm{a}$ monotherapy, this did not translate to higher rates of virological response after suspension of treatment [13]. A total of 17 $\mathrm{CHB}$ patients treated with a combination of Peg-INF- $\alpha-2 \mathrm{a}$ and ETV for 48 weeks and observed for an additional 24 weeks showed a significant decrease in serum $\mathrm{HBV}$ DNA [14].

The protocol of anti-viral therapy in these combination studies was not adjusted based on early response. Optimizing therapeutic regimens based on early virological response and individual characteristics would ensure that only patients who fail to achieve a good response with Peg-INF- $\alpha-2 \mathrm{a}$ monotherapy would receive combination therapy, thereby shortening the course of therapy, enhancing virological response, decreasing the economic burden and conserving medical resources $[15,16]$.

In this study, we aimed to investigate the influence of additional nucleoside analogues on the SVR and the improvement of liver histology in CHB patients who had a poor virological response to Peg-INF $\alpha-2 a$ at the end of 12 weeks of therapy.

\section{Methods}

\section{Patient recruitment}

A total of 178 patients diagnosed with $\mathrm{CHB}$ were recruited from the Department of Gastroenterology at China-Japan Union Hospital between September 2005 and December 2010. CHB diagnosis was based on the "Guideline for the Prevention and Therapy of Chronic Hepatitis B in China" issued by the Infectious Diseases Branch of the Chinese Medical Association, Hepatological Diseases Branch of the Chinese Medical Association, and the Chinese Foundation for Hepatitis Prevention and Control [17]. The study was performed in accordance with Good Clinical Practice and the ethical principles of the Declaration of Helsinki (ChiCTR-OCC-12002196). The study protocol was approved by a central independent ethics committee of China-Japan Union Hospital of Jilin University. All patients provided written informed consent.

Inclusion criteria were 1$) \mathrm{HBV}$ DNA $\geq 10^{4}$ copies $/ \mathrm{ml}$ (HBV DNA $\geq 300$ copies $/ \mathrm{ml}$ in the case of $\mathrm{CHB}$ patients with hepatic cirrhosis), 2) ALT $\geq U L N$, but $\leq 10 \times \mathrm{ULN}$ (normal or increased ALT in the case of CHB patients with hepatic cirrhosis), 3) serum total bilirubin $<2 \times$ ULN, 4) liver histological examination showing Knodell HAI $\geq 4$ or $\geq$ G2 inflammatory necrosis. Additionally, all study patients received anti-viral therapy with Peg-IFNo-2a. Exclusion criteria were 1) presence of decompensated cirrhosis, 2) history of mental illness, 3) presence of epilepsy, cancer or symptomatic heart diseases, 4) evidence of drug abuse or alcohol abuse, 5) concomitant infection with HCV, HDV or HIV. Breast-feeding and pregnant women were also excluded. 
This study was approved by the Institutional Review Board of the hospital, and informed consent was obtained from all study participants.

\section{Therapeutic protocol}

All study patients received a subcutaneous injection of Peg-IFN $\alpha-2 \mathrm{a}(180 \mu \mathrm{g})$ once weekly for 12 weeks. The therapeutic protocol was then adjusted based on virological response. A total of 138 patients had a poor virological response after 12 weeks of anti-viral therapy with Peg-IFN $\alpha-2 a$. After fully communication with patients,According to patients' willingness,Study patients were divided into 3 groups: (1) Patients in Group 1 (control group; $n=43$ ) were treated with Peg-IFN $\alpha-2 \mathrm{a}$ for 48 weeks and were followed for 48 weeks after therapy.

(2) Patients in Group $2(n=49)$ were treated with and $0.5 \mathrm{mg}$ of ETV once daily for 48 weeks and were followed for 48 weeks after therapy. (3) Patients in Group $3(n=46)$ were treated with Peg-IFN $\alpha-2 \mathrm{a}$ and $10 \mathrm{mg}$ of ADV once daily for 48 weeks and were followed for 48 weeks after therapy. Liver histological examination was performed in 38 of these patients before therapy and after follow-up, in order to evaluate the improvement of liver histology.

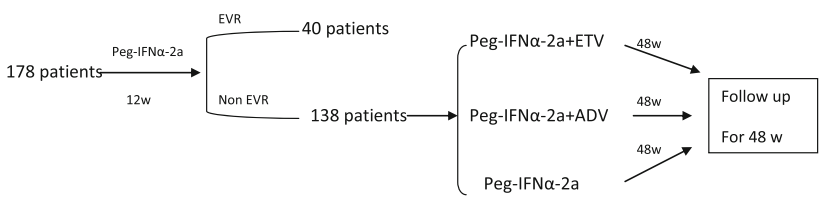

All study patients were subjected to a routine biochemical examination, routine urinalysis, and a routine blood test to evaluate thyroid function, and blood glucose levels. Patients were also evaluated for HBsAg levels, viral genotype. Routine blood tests were performed once weekly in the initial 4 weeks and thereafter once every 4 weeks. Biochemical examination and detection of HBV DNA and HBsAg levels were performed after 12 weeks of therapy, and once every 12 weeks thereafter. Patients receiving liver histological examination before therapy were evaluated for disease condition using the Knodell histology activity index (Knodell HAI) score, and were subjected to liver histological examination again after follow-up. Improvement in liver histology was defined as a reduction in Knodell score by $\geq 2$ when compared to the baseline score, and no deterioration of hepatic fibrosis (deterioration of hepatic fibrosis is defined as an increase in Knodell fibrosis score by $\geq 1$ ). Liver HBsAg levels were quantitated before and after anti-viral therapy in patients receiving liver histological examination.

\section{Evaluation of biochemical and virological markers}

Viral markers were detected by ELISA (Shanghai Kehua Biotech Co., Ltd). Serum HBsAg levels were semi-quantitatively evaluated with the ElecsysIIdetection system using the S-P method according to the manufacturer's instructions. Liver HBsAg expression was scored as $0,1,2,3$ and 4 based on cytoplasm and/or nuclear staining and as 25\%, 25-50\%, 50$75 \%$ and $>75 \%$ based on the proportion of positive hepatocytes to total hepatocytes [18]. Liver function was detected with an automatic biochemical analyzer (Beckman, USA). HBV DNA levels in the serum and liver tissue were quantitated by real time fluorescence PCR using an RT-PCR kit (lower limit of detection is 300 copies/ml; COBAS TaqMan 48; Roche, Meylan, France). HBV genotypes were determined by PCR microplate hybridization ELISA (Guangzhou Lanxing Biotech Co., Ltd) according to the manufacturer's instructions.

\section{Determination of therapeutic efficacy}

Early virological response was defined as undetectable HBV DNA after anti-viral therapy for 12 weeks. After 12 weeks of therapy, patients were followed for 48 weeks. Sustained virological response (SVR) was defined as no change in therapeutic effectiveness after 6 months follow-up, and no recurrence. SVR was calculated as the ratio of patients with HBV DNA lower than the lower detection limit $(<300$ copies $/ \mathrm{ml})$ to total patients.

Liver function was also re-examined regularly. However, it is important to note that patients treated with IFN and those with hepatic cirrhosis exhibit a transient increase in transaminases during anti-viral therapy with IFN. In addition, hepatic cirrhosis patients may occasionally exhibit a slight increase in transaminases although HBV DNA levels may be very low.

\section{Assessment of safety}

Side effects such as fever, muscle ache, fatigue and leukopenia were evaluated. The dose of Peg-IFN $\alpha-2 a$ dose was decreased when neutrophil counts reached $\leq 0.75 \times 10^{9} / \mathrm{L}$ or platelet counts reached $<50 \times 10^{9} / \mathrm{L}$; anti-viral therapy was stopped when the neutrophil count reduced to $\leq 0.5 \times 10^{9} / \mathrm{L}$ or platelet count reduced to $<30 \times 10^{9} / \mathrm{L}$.

\section{Determination of $\mathrm{HBeAg}$ conversion rate}

$\mathrm{HBeAg}$ seroconversion rate was calculated as the ratio of $\mathrm{HBeAg}$-positive patients who were $\mathrm{HBeAb}$-positive after anti-viral therapy to the total number of HBeAgpositive patients.

\section{Statistical analysis}

Patients' demographic and baseline characteristic data were presented as mean \pm standard deviations (SD) and median (IQR: 1st and 3rd quartiles) for continuous data with and without normal distribution; categorical data were presented as $n$ (\%). Differences among three groups were compared using one-way ANOVA and the Kruskall- 
Wallis test for continuous data with and without normal distribution, respectively; the Pearson Chi-square test was used for categorical ones.

The changes in HBV DNA levels after 4 wks, 12 wks, 24 wks, 36 wks, and 48 wks of treatment, and after 48 wks follow-up as compared with baseline HBV DNA levels were presented as mean \pm SD at each time point for a given treatment group. Differences in HBV DNA levels over time were compared between the treatment groups using repeated measurement ANOVA test with post-hoc Bonferroni pair-wise comparisons.

The HBV DNA SVR and HBsAg conversion rate were represented as percentage of rate for each group, and the change in HBsAg levels was represented as mean with standard deviation (SD) for each group. Differences between the groups were compared using the Pearson Chi-square test for HBV DNA SVR and HBsAg conversion rate and one-way ANOVA with a post-hoc Bonferroni pair-wise comparisons for change in HBsAg levels.

The Knodell score (necroinflammatory score), Ishak score (fibrosis score) and improvement of liver histology among three groups were represented as median (IQR: 1st, 3rd quartiles) for Knodell score and Ishak score; and $\mathrm{n}$ (\%) for improvement of liver histology. Differences between the groups were compared using the KruskallWallis test for Knodell and Ishak scores. The improvement of liver histology was compared using Fisher's exact test since some cell numbers were less than 5 .

The association of the change in HBsAg levels with each treatment and the association of improvement rate with the change in HBsAg levels were evaluated. The change in HBsAg levels was represented as mean \pm SD for each group and compared using one-way ANOVA with post-hoc Bonferroni pair-wise comparisons. The improvement rate was represented as percentages of patients for a given change in HBsAg levels. Differences between multiple changes in HBsAg levels were compared by Pearson Chi-square test.
All statistical assessments were two-tailed and $P<0.05$ was considered significant. An adjusted significance level of $0.0167(0.05 / 3)$ was considered for the post-hoc pairwise comparison, Bonferroni test. All statistical analyses were performed using the SPSS statistics software (SPSS Inc., Chicago, IL, USA).

\section{Results}

\section{Demographics and clinical characteristics}

After the first 12 weeks of Peg-IFN $\alpha$-2a treatment, a total of 43 study patients (24 males and 19 females) received Peg-IFN $\alpha-2 a$. Forty nine patients $(35$ males and 14 females) received Peg-IFN $\alpha-2 \mathrm{a}+\mathrm{ETV}$, and 46 patients (31 males and 15 females) received Peg-IFN $\alpha-2 a+$ ADV. The

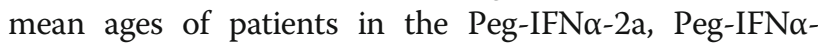
$2 \mathrm{a}+$ ETV, and Peg-IFN $\alpha-2 \mathrm{a}+$ ADV groups were 34.9 years $(\mathrm{SD}=10.9), 37.4$ years $(\mathrm{SD}=9.5)$, and 38.6 years $(\mathrm{SD}=10.0)$ respectively. There was no significant difference in the demographic data and baseline characteristics between the three groups (Table 1 ; all $P$ values $>0.05$ ).

\section{Efficacy of additional nucleoside analogues in patients treated with peg-IFNa-2a}

The temporal profiles of HBV DNA levels were evaluated before and after treatment (Fig. 1). Patients in the PegINF $\alpha-2 a+$ ETV as well as the Peg-INF $\alpha-2 a+$ ADV groups showed a significantly greater decrease in HBV DNA levels over time compared to the group treated with Peg-INF $\alpha-2 \mathrm{a}$ alone (both $P$ values $<0.0167$ ). Notably, Peg-INF $\alpha-2 \mathrm{a}+$ ETV and Peg-INF $\alpha-2 \mathrm{a}+$ ADV had similar efficacies, resulting in overlapping profiles after week 12 of treatment, but none patient achieve HBsAg loss during or after therapy (Fig. 1).

There was a significant difference in SVR between the three treatment groups (Fig. 2a). Patients in the PegIFN $\alpha-2 \mathrm{a}+$ ETV and Peg-IFN $\alpha-2 \mathrm{a}+$ ADV groups had significantly higher SVRs(69.4\%, and 71.7\%) compared to the group treated with Peg-IFN $\alpha-2$ a alone (32.6\%), both $P$ values $<0.001$.

Table 1 Demographic and baseline characteristic data of study patients

\begin{tabular}{|c|c|c|c|c|}
\hline Variables & $\begin{array}{l}\text { Peg-IFNa-2a } \\
(n=43)\end{array}$ & $\begin{array}{l}\text { Peg-IFNa-2a + ETV } \\
(n=49)\end{array}$ & $\begin{array}{l}\text { Peg-IFNa-2a + ADV } \\
(n=46)\end{array}$ & $P$ value \\
\hline Age & $34.86 \pm 10.86$ & $37.38 \pm 9.51$ & $38.63 \pm 9.98$ & 0.188 \\
\hline Sex, males (\%) & $24(55.8 \%)$ & $35(71.4 \%)$ & $31(67.4 \%)$ & 0.272 \\
\hline Baseline HBV DNA, ( $\log _{10}$ copies $/ \mathrm{mL}$ ) & $6.47 \pm 1.16$ & $6.48 \pm 1.01$ & $6.24 \pm 1.14$ & 0.513 \\
\hline Baseline ALT, U/L & $102(87,159)$ & $119(85,162)$ & $105(87.8,197.8)$ & 0.744 \\
\hline HBeAg status & & & & 0.905 \\
\hline positive & $28(65.1 \%)$ & $33(67.3 \%)$ & $32(69.6 \%)$ & \\
\hline negative & $15(34.9 \%)$ & $16(32.7 \%)$ & $14(30.4 \%)$ & \\
\hline Genotype & & & & 0.183 \\
\hline $\mathrm{B}$ & $10(23.8 \%)$ & $14(28.6 \%)$ & $19(41.3 \%)$ & \\
\hline C & $32(76.2 \%)$ & $35(71.4 \%)$ & $27(58.7 \%)$ & \\
\hline
\end{tabular}




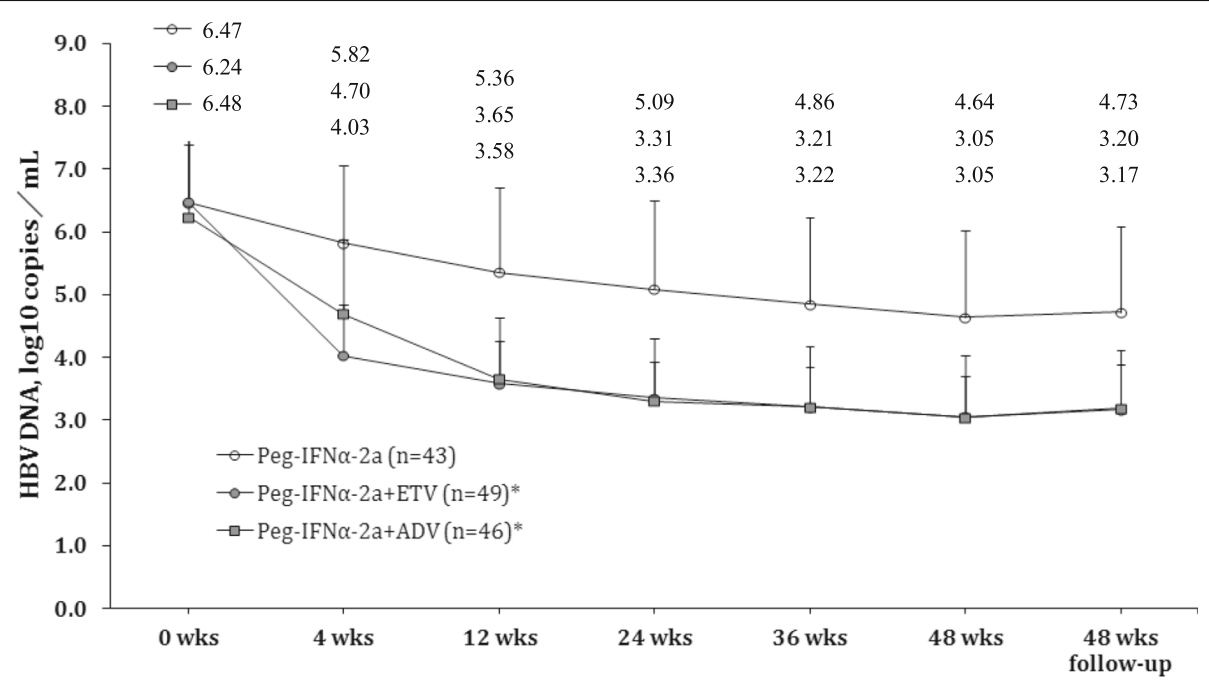

Fig. 1 Dispersion of HBV DNA before and after treatment for each group. Data were represented as mean \pm standard deviation (SD) for patients in Peg-IFNa-2a group, Peg-IFNa-2a + ETV group, and Peg-IFNa-2a + ADV group at baseline (0 wks), 4 wks, 12 wks, 24 wks, 36 wks, 48 wks of therapy, and 48 wks follow-up. Abbreviations: wks, weeks; ETV, Entecavir, $0.5 \mathrm{mg}$; ADV, Adefovir $10 \mathrm{mg}$. ${ }^{*} P<0.0167$, indicates a significant difference compared to the Peg-IFNa-2a group. There was no significant difference between the Peg-IFNa-2a + ETV and Peg-IFNa-2a + ADV groups

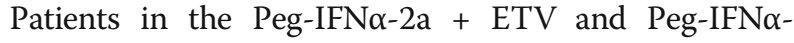
$2 \mathrm{a}+\mathrm{ADV}$ groups had higher HBeAg conversion rates compared to the group treated with Peg-IFN $-2 a$ alone, although these differences were not significant (Peg-IFNo2a vs. Peg-IFN $\alpha-2 \mathrm{a}+$ ETV: $14.3 \%$ vs. $24.2 \%, P=0.204$; Peg-IFN $\alpha-2 a$ vs. Peg-IFN $\alpha-2 a+$ ADV: $14.3 \%$ vs. $21.9 \%$, $P=0.339$ ) (Fig. 2b).

The changes in serum HBsAg levels compared to basal levels were evaluated at week 24 and week 48 of treatment and at 48 weeks after treatment. At each time point, patients in the Peg-IFNo-2a + ETV and PegIFN $\alpha-2 a+$ ADV groups exhibited significantly higher reduction in HBsAg levels compared to patients treated with Peg-IFN $\alpha-2$ a alone (both $P$ values $<0.0167$; Fig. 2c).

Thirty eight patients (11 in Peg-IFNo-2a group, 14 in PegIFN $\alpha-2 a+$ ETV group, and 13 in Peg-IFNo-2a + ADV group) received liver histological examinations before therapy and after the 48 week follow-up period. (Liver histological examination was performed in a fraction of the study patients since not all study patients were willing to undergo this procedure). There was no significant difference in any of these indices between the three groups (All $\mathrm{P}>0.05$ ). There was no significant difference in improvement of liver histology between the three groups (27.3\%, 64.3\% and 69.2\%

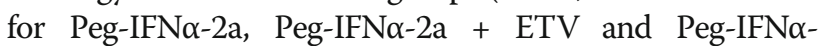
$2 \mathrm{a}+$ ADV groups, respectively; $P>0.05$ ) (Table 2).

The change in liver HBsAg levels was evaluated after 48 weeks of treatment in the $19 \mathrm{HBsAg}$-positive patients who received liver histological examination $(5$ in the Peg-

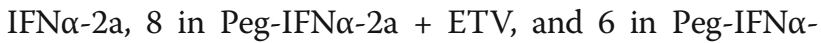
$2 \mathrm{a}+\mathrm{ADV}$. There was no significant difference $(P>0.05)$ in HBsAg levels between the three groups after 48 weeks of treatment (mean of 0.4 $(\mathrm{SD}=0.55)$ for the Peg-IFN $\alpha-2 \mathrm{a}$ group, 1.4 ( $\mathrm{SD}=1.06)$ for the Peg-IFN $\alpha-2 \mathrm{a}+$ ETV group, and 1.8 ( $\mathrm{SD}=1.2)$ for the Peg-IFN $\alpha-2 \mathrm{a}+\mathrm{ADV}$ group).

The rate of improvement versus the change in $\mathrm{HBsAg}$ levels was calculated in the $19 \mathrm{HBsAg}$-positive patients who received liver histological examination. The rate of improvement was $100 \%(3 / 3)$ in patients who had a change in HBsAg level $=3$. The rate of improvement was $60 \%(3 / 5)$ in patients who had a change in HBsAg level $=2$; $40 \%(2 / 5)$ in patients who had a change in HBsAg level $=1$, and $50 \%(3 / 6)$ in patients who had a change in HBsAg level $=0$. There was no significant association between rate of improvement versus the change in HBsAg levels $(P=0.459)$.

All study patients were monitored for adverse events. The most common adverse events reported were fatigue and muscle ache, fever, and thrombocytopenia (Table 3).

\section{Discussion}

In this study, patients who had a poor virological response after 12 weeks of Peg-IFN $\alpha$-2a monotherapy were treated for an additional 48 weeks with a combination of PegIFN $\alpha-2 a+$ ETV or Peg-IFN $\alpha-2 a+$ ADV. Both regimens of combination therapy resulted in a significantly greater decrease in HBV DNA levels over time, and a significantly higher SVR compared to Peg-INF $\alpha$-2a monotherapy. Although patients receiving combination therapy had a significantly higher change in serum HBsAg levels compared to the monotherapy group, there was no significant difference in liver HBsAg levels between the three treatment groups. 


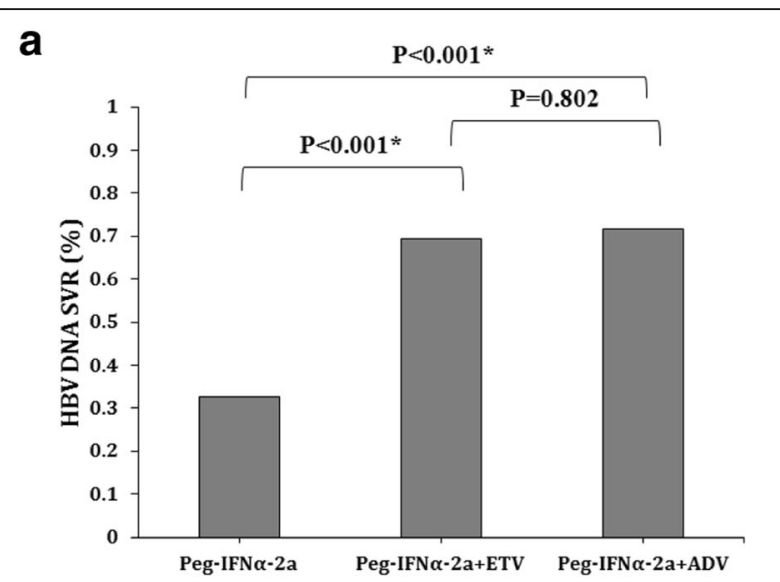

b

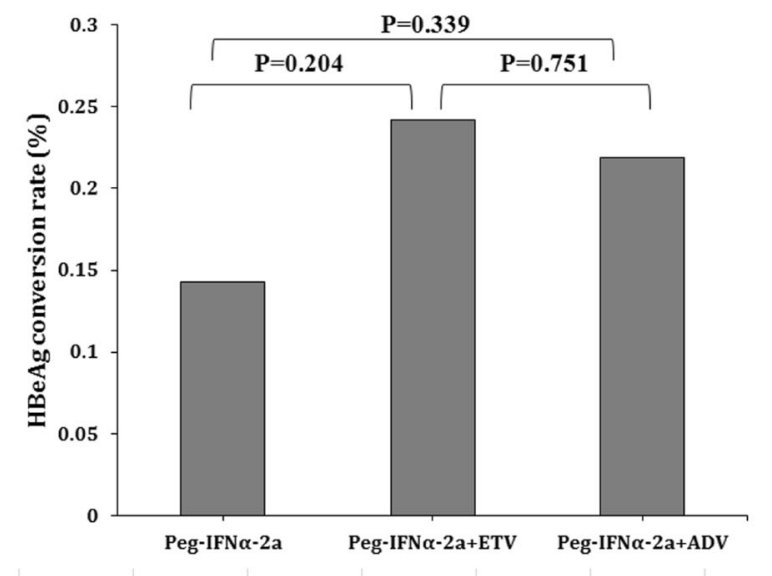

C

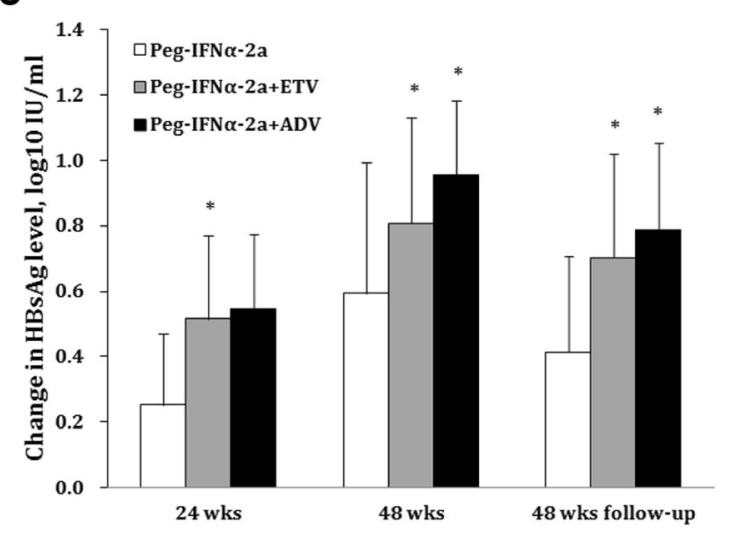

Fig. 2 Summary of HBV DNA SVR (a), HBeAg conversion rate (b), and change in serum HBsAg levels after treatments (c) by groups. The change in HBsAg levels after therapy was calculated as the difference between baseline HBsAg level and the HBsAg level at a specific time point. HBV DNA SVR was represented as percentage of rate and the change in $\mathrm{HBs} A g$ levels was represented as mean with standard deviation (SD). $P<0.001$, indicates a significant difference
A number of studies have investigated therapeutic strategies which combined the immunomodulatory effects of Peg-IFNo-2a along with the direct anti-viral activity of NAs for patients with a poor response to anti-viral therapy. The addition of LAM to Peg-IFN therapy failed to enhance therapeutic efficacy compared to monotherapy in early studies $[9,10,19]$. However, a recent meta-analysis suggested that a combination of PEG-IFN and LAM increased SVR [20]. A combination of Peg-IFN with ADV or ETV for 48 weeks had a significantly higher therapeutic efficacy in HBeAg-negative $\mathrm{CHB}$ patients compared to Peg-IFN monotherapy [14, 21]. A recent study showed the efficacy of a sequential treatment strategy where patients received 24 weeks of telbuvidine followed by 24 weeks of Peg-IFN $\alpha-2 \mathrm{a}$ [22]. It is important to note that these studies used combination therapy as the first-line therapy, whereby patients having the potential to achieve a virological response with Peg-IFN alone also received combination therapy. In the present study, 138 study patients were treated Peg-IFNo-2a for 12 weeks, and only 95 patients who had a poor virological response at the end of this period received combination therapy of Peg-IFNo-2a with either ETV or ADV for 48 weeks. The Peg-IFN$\alpha 2 \mathrm{a}+$ ETV and Peg-IFN- $\alpha 2 \mathrm{a}+$ ADV groups showed a reduction in HBV DNA by 3.3 and $3.0 \log _{10}$ copies $/ \mathrm{mL}$, respectively and the proportion of patients with undetectable HBV DNA was $69.4 \%$ and $71.7 \%$, respectively, which were significantly higher than that in patients treated with Peg-IFN $\alpha$-2a alone.

Anti-viral therapy with Peg-IFN was shown to improve liver histology in $38-48 \%$ of patients and significantly delay disease progression [23]. A meta-analysis of 26 prospective studies also revealed that reduction of HBV DNA levels after anti-viral therapy was positively related to improvement of liver histology [24]. In the present study, a significantly higher percentage of patients in the Peg-IFN$\alpha 2 \mathrm{a}+$ ADV and Peg-IFN- $\alpha 2 \mathrm{a}+$ ETV groups showed an improvement in liver histology compared to the PegIFN $\alpha-2$ a monotherapy group ( $69.2 \%$ and $64.3 \%$ vs. $27.3 \%)$. These data suggested that in patients with an early poor virological response to Peg-IFN- $\alpha 2 a$, addition of NAs could promote inhibition of viral replication, which is associated with SVR and improvement of liver histology. These findings have important implications for attenuation of hepatic inflammation and fibrosis and slowing the progression of hepatic cirrhosis in CHB patients.

Baseline and on-treatment HBsAg levels have been shown to be strong predictors of therapeutic efficacy, and patients with HBsAg levels $>20,000 \mathrm{IU} / \mathrm{ml}$ after 24 weeks of Peg-IFN $\alpha$-2a treatment failed to achieve a virologic response [25]. Reduction in HBsAg levels has been shown to be closely related to seroconversion of HBeAg and HBsAg, and a larger reduction in HBsAg levels during therapy is associated with a higher possibility of HBsAg 
Table 2 Knodell and Ishak scores before and after anti-viral therapy and improvement of liver histology after anti-viral therapy in the three treatment groups $(N=38)$

\begin{tabular}{|c|c|c|c|c|}
\hline Variables & $\begin{array}{l}\text { Peg-IFNa-2a } \\
(n=11)\end{array}$ & $\begin{array}{l}\text { Peg-IFNa-2a + ETV } \\
(n=14)\end{array}$ & $\begin{array}{l}\text { Peg-IFNa-2a + ADV } \\
(n=13)\end{array}$ & $P$ value \\
\hline \multicolumn{5}{|l|}{ Before anti-viral therapy } \\
\hline Ishak score & $3(2,3)$ & $3(2,4)$ & $4(3,4)$ & 0.070 \\
\hline Knodell score & $6(5,7)$ & $6(4.7,7)$ & $6(5,7.5)$ & 0.154 \\
\hline \multicolumn{5}{|l|}{ After anti-viral therapy } \\
\hline Ishak score & $3(2,3)$ & $2.5(2,3.3) a$ & $3(2.5,3.5) a$ & 0.613 \\
\hline Knodell score & $4(4,5) b$ & $4(3,5) b$ & $4(3,6) b$ & 0.573 \\
\hline Improvement of liver histology & $3(27.3 \%)$ & $9(64.3 \%)$ & $9(69.2 \%)$ & 0.083 \\
\hline
\end{tabular}

Data were represented as median (IQR: 1st, 3rd quartiles) for Knodell score and Ishak score; and n (\%) for improvement of liver histology

Differences between groups were compared using the Kruskall-Wallis test for Knodell and Ishak scores; Differences between pre- and post-inflammation were

compared using the Wilcoxon Sign-rank test because the Knodell score and Ishak score were ordinal data. The improvement of liver histology was compared using Fisher's exact test since some cell numbers were less than 5

There was no significant difference between the groups

ab $P<0.05$, significant difference compared with pre-treated a (Ishak score) and b (Knodell score) for a given group

loss after long-term anti-viral therapy [26-29]. However, the association between serum HBsAg levels and liver histological score and HBV DNA levels remains unclear. One study reported that serum HBsAg levels were negatively associated with HBV DNA levels [30], while another study showed that 1) HBV DNA in the liver of CHB patients and HBV cccDNA before therapy were positively related to serum $\mathrm{HBsAg}$, and 2) the reduction in serum $\mathrm{HBsAg}$ was positively associated with the reduction in HBV DNA in the liver and HBV cccDNA after combination therapy with LAM and Peg-IFN [31, 32]. In the present study, we showed that patients in the Peg-IFN- $\alpha$ $2 \mathrm{a}+$ ADV and Peg-IFN- $\alpha-2 \mathrm{a}+$ ETV groups had a more significant change in serum HBsAg levels compared to patients in the Peg-IFN- $\alpha$-2a monotherapy group, as well as a higher rate of HBsAg seroconversion. Our data suggested that using combination therapy to achieve modulation of the immune response by Peg-IFN $\alpha-2 \mathrm{a}$ and inhibition of viral inhibition by Peg-IFN $\alpha-2 a$ and NAs,

Table 3 Summary of adverse events

\begin{tabular}{lll}
\hline Adverse events & $\begin{array}{l}\text { Peg-IFNa-2a } \\
(n=43)\end{array}$ & $\begin{array}{l}\text { Combination } \\
\text { groups }(n=95)\end{array}$ \\
\hline Fatigue and muscle ache & $36(83.7 \%)$ & $76(80 \%)$ \\
Fever & $30(70 \%)$ & $70(73.7 \%)$ \\
Thrombocytopenia & $22(51.2 \%)$ & $47(49.5 \%)$ \\
Anemia & $16(37.2 \%)$ & $36(37.9 \%)$ \\
Neutropenia & $14(32.6 \%)$ & $33(34.7 \%)$ \\
Loss of appetite & $15(34.9 \%)$ & $30(31.6 \%)$ \\
Hair Loss & $10(23.3 \%)$ & $24(25.3 \%)$ \\
Abnormal blood glucose & $2(4.7 \%)$ & $5(5.3 \%)$ \\
Rash & $2(4.7 \%)$ & $3(3.2 \%)$ \\
Hypothyroidism & $1(2.3 \%)$ & $1(1.1)$ \\
\hline
\end{tabular}

Data were summarized as $\mathrm{n}(\%)$ for given adverse events in each group significantly enhanced therapeutic efficacy which was reflected by a reduction in serum HBsAg. However, there was no correlation between change in liver HBsAg levels and rate of improvement in liver histology. The current study about the relation of serum HBsAg and liver histologic is not very clear, all the results are also different. This study not only observed the changes of serum HBsAg levels, also for the iver histologic HBsAg levels, designed to examine whether changes in the level of HBsAg can predict the effect. But because the patients with liver histological examination is less, the results found no significant differences.

We aimed to investigate the influence of additional nucleoside analogues on the SVR and the improvement of liver histology in $\mathrm{CHB}$ patients who had a poor virological response to Peg-INFo-2a at the end of 12 weeks of therapy. We can further observe the effect of sequential interferon therapy following nucleoside analogue for a long time .

\section{Conclusions}

In summary, this study demonstrated that in patients with a poor virological response after 12 weeks of treatment with Peg-IFNa-2a alone, addition of ADV or ETV significantly reduced HBV DNA levels, serum HBsAg levels, and increased SVR. Individualization of anti-viral therapy would ensure that only patients who do not respond to Peg-IFN $\alpha$-2a would receive combination therapy. Our data have important implications for the treatment of $\mathrm{CHB}$ patients who fail to show an early response to PegIFN $\alpha$-2a monotherapy.

\footnotetext{
Abbreviations

ADV: adefovir dipivoxil; cccDNA: covalently closed circular HBV DNA; CHB: chronic hepatitis B; ETV: entecavir; HBV: hepatitis B virus; HCC: hepatocellular carcinoma; LAM: lamivudine; PEG-IFN-a-2a: pegylated interferon alpha 2a; SVR: sustained virologic response
} 


\section{Acknowledgements}

Medica Communicus Zhuhai Ltd. provided writing assistance which was sponsored by Shanghai Roche Pharmaceuticals Ltd.

\section{Authors' contribution}

$Y X$ and JBW participated in the study design and coordination and the manuscript preparation. XW and ZHL performed the biochemical and virological assays. CYZ, JJ, FY, HHG, PZ participated in the implementation of the study. WQQ participated in study design and performed the statistical analysis. All authors read and approved the final manuscript.

\section{Funding}

This study was supported by a grant from the Key projects of Science and Technology Agency of Jilin province (grant no: 20,090,440)

\section{Availability of data and materials}

The datasets generated and/or analysed during the current study are not publicly available in order to ensure patient confidentiality, but are available from the corresponding author on reasonable request.

\section{Ethics approval and consent to participate}

The study protocol was approved by a central independent ethics committee of China-Japan Union Hospital of Jilin University. All patients provided written informed consent.

\section{Consent for publication}

Not applicable.

\section{Competing interests}

Writing assistance was sponsored by Shanghai Roche Pharmaceuticals Ltd.

\section{Publisher's Note}

Springer Nature remains neutral with regard to jurisdictional claims in published maps and institutional affiliations.

\section{Received: 26 January 2017 Accepted: 17 August 2017}

Published online: 30 August 2017

\section{References}

1. Liang TJ. Hepatitis B: the virus and disease. Hepatology. 2009;49(5 Suppl): S13-21.

2. Janssen HL, van Zonneveld M, Schalm SW. Hepatitis B. N Engl J Med. 2004 350(26):2719-20

3. Lai CL, Ratziu V, Yuen MF, Poynard T. Viral hepatitis B. Lancet. 2003; 362(9401):2089-94

4. European Association For The Study Of The L. EASL clinical practice guidelines: management of chronic hepatitis B virus infection. J Hepatol. 2012:57(1):167-85.

5. Lok AS, McMahon BJ. Chronic hepatitis B: update 2009. Hepatology. 2009; 50(3):661-2.

6. Liaw YF, Chien RN, Yeh CT, Tsai SL, Chu CM. Acute exacerbation and hepatitis $B$ virus clearance after emergence of YMDD motif mutation during lamivudine therapy. Hepatology. 1999;30(2):567-72.

7. Manesis EK, Hadziyannis SJ. Interferon alpha treatment and retreatment of hepatitis B e antigen-negative chronic hepatitis B. Gastroenterology. 2001; 121(1):101-9.

8. Sonneveld MJ, Zoutendijk R, Hansen BE, Janssen HL. Pegylated interferon results in higher serological, but not virological, response rates when compared to continuous entecavir. Antivir Ther. 2012;17(8):1605-8.

9. Lau GK, Piratvisuth T, Luo KX, Marcellin P, Thongsawat S, Cooksley G, et al. Peginterferon alfa-2a, lamivudine, and the combination for HBeAg-positive chronic hepatitis B. N Engl J Med. 2005;352(26):2682-95.

10. Marcellin P, Lau GK, Bonino F, Farci P. Hadziyannis S, Jin R, et al. Peginterferon alfa-2a alone, lamivudine alone, and the two in combination in patients with HBeAg-negative chronic hepatitis B. N Engl J Med. 2004; 351(12):1206-17. https://doi.org/10.1056/NEJMoa040431.

11. Karabay O, Tuna N, Esen S, Group P-HS. Comparative efficacy of pegylated interferons alpha-2a and $2 \mathrm{~b}$ in the treatment of HBeAg-negative chronic hepatitis B infection. Eur J Gastroenterol Hepatol. 2012;24(11):1296-301.

12. Gulsun S, Tekin R, Bozkurt F. Treatment of chronic delta hepatitis: a nineyear retrospective analysis. Hepat Mon. 2011;11(9):731-5.
13. Piccolo P, Lenci I, Demelia L, Bandiera F, Piras MR, Antonucci G, et al. A randomized controlled trial of pegylated interferon-alpha2a plus adefovir dipivoxil for hepatitis B e antigen-negative chronic hepatitis B. Antivir Ther. 2009;14(8):1165-74.

14. Hagiwara S, Kudo M, Osaki Y, Matsuo H, Inuzuka T, Matsumoto A, et al. Impact of peginterferon alpha-2b and entecavir hydrate combination therapy on persistent viral suppression in patients with chronic hepatitis B. J Med Virol. 2013:85(6):987-95.

15. Fried MW, Piratvisuth T, Lau GK, Marcellin P, Chow WC, Cooksley G, et al. $\mathrm{HBeAg}$ and hepatitis B virus DNA as outcome predictors during therapy with peginterferon alfa-2a for HBeAg-positive chronic hepatitis B. Hepatology. 2008:47(2):428-34.

16. Zoulim F, Perrillo R. Hepatitis B: reflections on the current approach to antiviral therapy. J Hepatol. 2008:48(Suppl 1):S2-19.

17. Branch of Infectious Diseases and Parasitic Diseases of Chinese Medical Association BoHDoCMAaCFfHPaC. Chinese J Hepatol. 2008;8(6):6.

18. Lindh M, Savage K, Rees J, Garwood L, Horal P, Norkrans G, et al. HBeAg immunostaining of liver tissue in various stages of chronic hepatitis B. Liver. 1999;19(4):294-8.

19. Janssen $H L$, van Zonneveld M, Senturk H, Zeuzem S, Akarca US, Cakaloglu Y, et al. Pegylated interferon alfa-2b alone or in combination with lamivudine for HBeAg-positive chronic hepatitis B: a randomised trial. Lancet. 2005; 365(9454):123-9.

20. Shi Y, Wu YH, Shu ZY, Zhang WJ, Yang J, Chen Z. Interferon and lamivudine combination therapy versus lamivudine monotherapy for hepatitis B e antigen-negative hepatitis B treatment: a meta-analysis of randomized controlled trials. Hepatobiliary Pancreat Dis Int. 2010;9(5):462-72.

21. Piccolo P, De Melia, L, Bandiera F, et al. Peginterferon alpha-2a plus adefovir dipivoxil vs. peginterferon alpha-2a monotherapy for 48 weeks in $\mathrm{HBeAg}$ negative chronic hepatitis $B$ : final results of the PEG for $B$ randomized multicenter trial. Digestive Disease Week. 2008;May 17-22(Abstract 256).

22. Piccolo P, Lenci I, di Paolo D, Demelia L, Sorbello O, Nosotti L, et al. A randomized controlled trial of sequential pegylated interferon-alpha and telbivudine or vice versa for 48 weeks in hepatitis B e antigen-negative chronic hepatitis B. Antivir Ther. 2013;18(1):57-64.

23. Cooksley WG, Piratvisuth T, Lee SD, Mahachai V, Chao YC, Tanwandee T, et al. Peginterferon alpha-2a (40 kDa): an advance in the treatment of hepatitis B e antigen-positive chronic hepatitis B. J Viral Hepat. 2003;10(4):298-305.

24. Mommeja-Marin H, Mondou E, Blum MR, Rousseau F. Serum HBV DNA as a marker of efficacy during therapy for chronic HBV infection: analysis and review of the literature. Hepatology. 2003;37(6):1309-19.

25. Sonneveld MJ, Hansen BE, Piratvisuth T, Jia JD, Zeuzem S, Gane E, et al. Response-guided peginterferon therapy in hepatitis $B$ e antigen-positive chronic hepatitis B using serum hepatitis B surface antigen levels. Hepatology. 2013;58(3):872-80.

26. Moucari R, Korevaar A, Lada O, Martinot-Peignoux M, Boyer N, Mackiewicz V et al. High rates of $\mathrm{HBsAg}$ seroconversion in $\mathrm{HBeAg}$-positive chronic hepatitis B patients responding to interferon: a long-term follow-up study. J Hepatol. 2009;50(6):1084-92.

27. Brunetto MR, Moriconi F, Bonino F, Lau GK, Farci P, Yurdaydin C, et al. Hepatitis B virus surface antigen levels: a guide to sustained response to peginterferon alfa-2a in HBeAg-negative chronic hepatitis B. Hepatology. 2009;49(4):1141-50.

28. Manesis EK, Hadziyannis ES, Angelopoulou OP, Hadziyannis SJ. Prediction of treatment-related $\mathrm{HBsAg}$ loss in $\mathrm{HBeAG}$-negative chronic hepatitis B: a clue from serum HBsAg levels. Antivir Ther. 2007:12(1):73-82.

29. Tangkijvanich $P$, Komolmit $P$, Mahachai $V$, Sa-nguanmoo $P$, Theamboonlers A, Poovorawan $Y$. Low pretreatment serum HBsAg level and viral mutations as predictors of response to PEG-interferon alpha-2b therapy in chronic hepatitis B. J Clin Virol. 2009:46(2):117-23.

30. Ozdil B, Cosar AM, Akkiz H, Sandikci MU, Kece C. Negative correlation between viral load and HBsAg levels in chronic HBV-infected patients. Arch Virol. 2009;154(9):1451-5.

31. Chan HL, Wong WW, Chim AM, Chan HY, Wong GL, Sung JJ. Serum HBsAg quantification to predict response to peginterferon therapy of e antigen positive chronic hepatitis B. Aliment Pharmacol Ther. 2010;32(11-12):1323-31.

32. Chan HL, Wong WW, Tse AM, Tse $\mathrm{CH}$, Chim AM, Chan HY, et al. Serum hepatitis $B$ surface antigen quantitation can reflect hepatitis $B$ virus in the liver and predict treatment response. Clin Gastroenterol Hepatol. 2007:5(12): $1462-8$ 